\title{
He nature of mining input technology in South Africa
}

\author{
by P. Leeuw* and H. Mtegha*
}

\section{Synopsis}

The aim of this paper is to enhance the understanding of the nature of mining input technologies in the South African mining industry. In the context of this research, mining inputs refer to input technology into the activities in mining engineering fields, which include mining-related production activities, rock engineering, mine ventilation, and mine transportation (handling of personnel, material, broken rock, and pumping). Input technologies in supporting fields such as geology, other engineering disciplines, human resource, procurement, finance, as well as downstream fields that include metallurgy, and marketing of minerals, were disregarded.

The mining input technologies were divided into 12 nodes, and data from a sample of 150 first-tier mining suppliers was analysed. It was found that, in general, there is a high local content in mining input technologies, particularly as regards technical support services, artefacts, and machine technologies. This points to the presence of mining-induced backward linkages in the South African mining industry. The majority $(83 \%)$ of companies that provide input technologies into mining are located in Gauteng Province, and relatively few are found in provinces where mining is concentrated such as North-West, Limpopo, Mpumalanga, and Free State.

\section{Keywords}

mining input technology; backward linkages; South African mining industry. the South African economy is also

demonstrated by its sustained average contribution of $33 \%$ to the total export account in the past decade (Chamber of Mines of South Africa, 2014). Hausmann and Klinger (2006) view this as a weakness, because firstly, minerals are exported as commodities with very little differentiation; and secondly, minerals are a fixed natural endowment that is gradually depleted, while the population and its diverse needs increase over time.

Export sophistication arises when new products that require a higher knowledge intensity and various inputs are developed for export markets. Merely increasing the production of existing products constitutes an increase in productivity, but not in export sophistication. A good measure of export sophistication is an increase in the activities of the secondary and tertiary sectors of the economy. For mineral-endowed economies, part of the increase in these activities should be due to the linkage effect between the primary sector and the secondary and tertiary sectors.

\section{Economic linkages}

The development of the resource linkage effect theory, especially for developing countries, can largely be attributed to balanced and unbalanced growth doctrines. The concept of balanced growth is attributed to the GermanAmerican economist Friedrich List (17891846) (Clairmonte, 1959; Streeten, 1959). List held an opinion that economic prosperity and liberty can be realized when a nation systematically progresses from primary sector activities to secondary and tertiary sector

* University of the Witwatersrand, Johannesburg, South Africa.

(c) The Southern African Institute of Mining and Metallurgy, 2016. ISSN 2225-6253. Paper received Apr. 2016; revised paper received Sep. 2016. 


\section{The nature of mining input technology in South Africa}

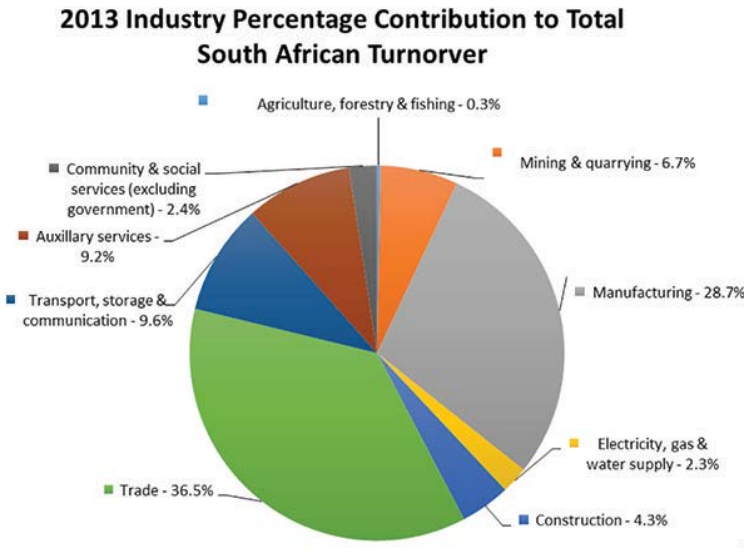

Figure 1-Percentage contribution per economic sector to the total 2013 turnover in South Africa (Statistics South Africa, 2014)

activities. The balanced growth doctrine prescribes that all sectors of the economy must develop simultaneously over time to usher in a new period of economic prosperity.

The criticism of balanced growth, and therefore support for unbalanced growth, came from economists such as Albert Hirschman and Paul Streeten. Hirschman (1958) was of the view that in an economy, any form of investment upsets equilibrium and results in new demands that bring about unbalance. According to Hirschman, any investment aimed at meeting new demands after the initial investment will lead to further unbalance (disturbance) in the market. Therefore, a balanced state (simultaneous development of all sectors of the economy) is unattainable, and the best way of achieving economic growth is to target sectors that have the potential to grow and stimulate multipliers in other sectors or industries, rather than the blanket approach of balanced growth.

The initial investment and subsequent reinvestments to meet new demands in the economy under the unbalanced growth doctrine lead to linkages or connectedness between various sectors. These linkages can be best illustrated through the input-output model. The work of Hirschman and others over the years uncovered a number of linkage types in the economy.

> Production linkages, consisting of forward and backward linkages (Hirschman, 1958) and sideways linkages (Walker and Jourdan, 2003; Lydall, 2009). These arise due to transactions between different sectors of the economy

> Consumption linkages (Hirschman, 1992, p. 64). These arise due to the demand for products and services as a consequence of earned income

> Fiscal linkages (Hirschman, 1981). These arise when tax receipts from exports and imports (tariffs) are invested to create new or enhance existing public goods

> Spatial linkages (Mtegha et al., 2012). These arise when infrastructure (especially social overhead capital) is built as a result of the exploitation of a resource in a region

> Lateral migration linkages (Walker and Jourdan, 2003). These arise when technology originally used in one industry is adapted to meet new demands in other industries.
These linkages types resonate with opportunities that the African Mining Vision seeks to create for the African mineral sector, which are:

'(i) increasing local upstream support (supplier/input industries) sectors; (ii) enhancing downstream industries based on increased local beneficiation and value addition of goods; (iii) facilitating lateral migration of mining technologies to other industries; (iv) increasing social, human, knowledge and institutional capital (which can be used in other sectors); (v) promoting the development of sustainable livelihoods in mining communities; and (vi) creating small-and medium-sized enterprises and a more balanced and diversified economy with greater multiplier effects and potential to create employment' (African Union, 2009, p. 5).

It should be noted that the central aim of the African Mining Vision 'is to move mining out of its enclaves and turn it into a sector that can catalyse and contribute to the broadbased growth and development of a single African market, within which it will be fully integrated. This requires work, sector by sector and region by region, to build both downstream linkages into mineral beneficiation and manufacturing, and also upstream linkages into mining capital goods, consumables and service industries' (DlaminiZuma, 2014, p. 58)

A large part of mining linkages is manufacturing. In South Africa there has been a slight but general decline in manufacturing production since 2010, presumably due to depressed economic conditions in Europe and the USA. This has led to the underutilization of capacity by $2 \%$ compared to the period prior to the 2008 credit meltdown. Similarly, there has been a decline in bulk mineral shipping prices and the bulk mineral price index since 2009. These local and global trends have put pressure on the domestic manufacturing sector, and some companies are starting to ponder mechanization and automation (Manufacturing Circle, 2015).

Potential obstacles as companies turn to mechanisation and automation in the manufacturing sector in South Africa is the shrinkage of skilled artisans and engineers at a rate of $0.9 \%$ and $0.5 \%$ respectively from 2002 and 2013 and the marginal growth of technicians at a rate of $0.7 \%$ over the same period. This trend could be reversed by attracting young Africans and women into technical fields. The percentage of African artisans increased from $40 \%$ in 2002 to over $80 \%$ in 2013; however, unfortunately the percentage of women dropped from $35 \%$ in 2002 to $25 \%$ in 2012 . The reason for the decline in female artisans is not clear, but this trend is a cause for concern (Department of Trade and Industry, 2015).

Notwithstanding, the focus of this paper is on production linkages, in particular backward linkages or inputs into mining. When the flow of inputs from supplier industries into mining industry is strong, then the subsequent multipliers into the economy should also be strong. Mines globally generate multipliers (Lagos and Blanco, 2010; Ge and Lei, 2013; Fleming and Measham, 2014), and South Africa is no exception. In particular, according to Jones and Baxter (2002, pp.83-84), mines in South Africa generate social, primary income, employment outside the mining industry, income in terms of trade, and capital formation multipliers as briefly outlined in Table I.

If, for example, we consider the employment multiplier as outlined in Table I, it is found that in 2013 the South African 


\section{The nature of mining input technology in South Africa}

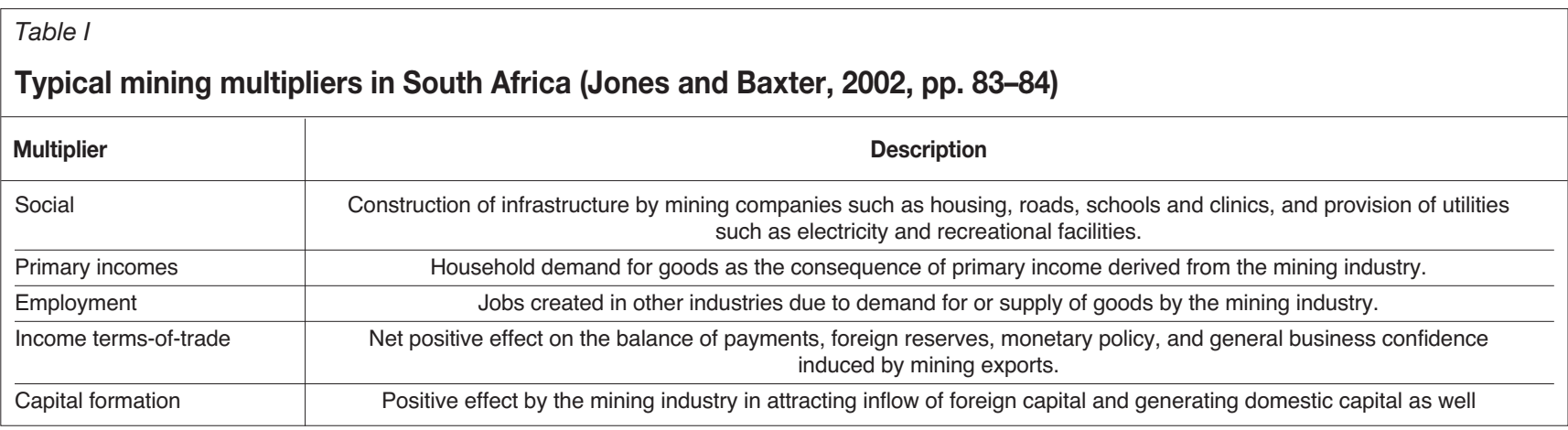

mining industry's turnover was R469.8 billion (R524.5 billion when investments, trademarks, and other sources are taken into account) against the total expenditure of R495.2 billion. A total of R214.1 billion or $43.2 \%$ of the total expenditure was spent on purchasing goods and services. (Chamber of Mines of South Africa, 2014). Expenditure on goods and services is important as it largely represents backward linkages into the economy.

The ability to locally manufacture and provide mining inputs is a better leverage for a country. It should be noted that the nature of mining lends itself to an enclaved structure and countries should be vigilant against such, lest they find their mining industry linked to local industries through international markets as eloquently stated by Lombard and Stadler (1980). That is, there is a tendency for international suppliers (manufacturers and service providers) to set up agencies locally through which procurements are channelled back to base companies where intellectual properties are held and which ultimately constitute a sink for a large portion of the procurement value.

Walker and Jourdan (2003, p. 36), in a study commissioned by the Chamber of Mines of South Africa in 2000, stated that 'South Africa has used its mining activities as a base to nurture a cluster of highly competitive mining and mineral processing-related goods and services industries, supporting both local and international markets'. This statement is supported by the work of Kaplan (2011), which showed that South Africa was a net exporter of mining equipment, with a $37 \%$ market share in sub-Saharan Africa in 2009. This type of backward linkage is important for job creation outside the mining industry.

\section{Motivation for the research}

The assertions by Walker and Jourdan (2003, p. 36) and Kaplan (2011) motivated an investigation into what type of mining inputs are in demand in the South African mining industry. In the context of this research, mining inputs refers to technology inputs into activities in the mining engineering fields, which include mining-related production activities, rock engineering, mine ventilation, and mine transportation (handling of personnel, material, broken rock, and pumping). Input technologies in supporting fields such as geology, other engineering disciplines, human resources, procurement, finance, and downstream fields that include metallurgy and marketing of minerals are excluded in this case.

The aim was to isolate mining from other disciplines with the view of creating an understanding of the nature of its backward linkages. Figure 2 shows the focus area of this paper along the mineral value chain.

To achieve this aim, a sample of 150 companies registered in South Africa and which provide the local mining industry with inputs and services was compiled from information in various local mining magazines and trade booklets. The following criteria were used in the selection:

> Companies must be registered in South Africa, irrespective of their country of origin

- They must be first-tier suppliers, i.e. they must supply the mines directly with their products and/or services (Lydall, 2009)

> They must offer mining input technology (products and services).

It is worth mentioning that some of the companies in the sample are also suppliers to other industries. This points to the presence of sideways linkages and even perhaps lateral migration linkages, neither of which are discussed in this paper.

Once the sample was established, company activities were analysed against the four-digit Standard Industrial Classification (SIC) code. The SIC code helped to differentiate between manufacturing and services, and locally manufactured and imported goods. The analysis identified 44 distinct activities (see Appendix A). Collectively, there were a total of 390 activities performed by the 150 companies in the sample. The company activities according to the SIC code are a good indication of the input technology and its origin.

\section{The nature of mining input technology}

In order to analyse the activities of supply companies and the product and services they provide, it was imperative to unpack what is meant by the term 'technology'. Macdonald (1985) states that technology can be described as simply the way things are done, i.e. how we drink coffee in the morning or consume news. Mitcham (1994) came up with the concept

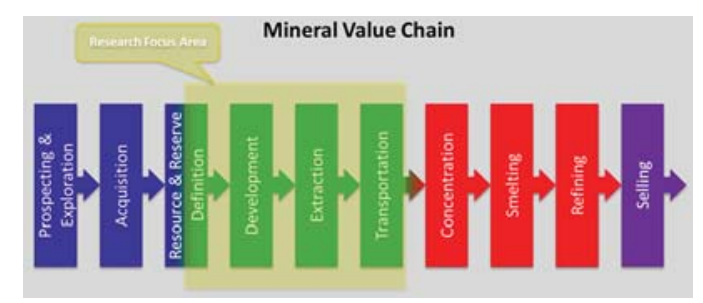

Figure 2-Research focus area as viewed along the mineral value chain 


\section{The nature of mining input technology in South Africa}

of narrow and broad perspectives of technology. The narrow perspective is associated with machinery and artefacts, whereas the broad perspective is associated with what people do in the presence of a technology (social system).

Lowe (1995) described what Mitcham called the narrow perspective of technology as a branch of human knowledge that applies scientific principles and practical knowledge to physical entities and systems. Lowe's description is useful in that it defines a paradigm through which technology in engineering applications can be analysed. While engineers ought to understand the social perspective of technology, it is imperative they understand the scientific principles behind physical entities and systems that make up a technology. It is this understanding that was used to categorize and classify mining technology in this paper.

From the analysis, four categories of technology types were identified. Furthermore, each category was divided into three classes based on the level of sophistication of the technology or its application in mining. The categorization and subsequent classification of input mining technology thus resulted in 12 nodes of technology as shown in Table II.

\section{Artefact technology category}

Artefact technology refers to the application and performance of individual artefacts such as objects, machine parts, and computer components used as inputs into mining activities. The simplest class of this category comprises single and isolated components, which on their own or in conjunction with others can be used for a specific task, e.g. a shank in a drifter. The second class consists of assemblages of artefacts to produce a unique device, e.g. the combination of a rod, plate, and nut in a roofbolt. The third class consists of an assemblage of artefacts to produce tools with networking ability, e.g. heat or smoke sensors.

\section{Machine technology category}

Machine technology can be described as technology that replaces or enhance muscular effort in doing work. It is divided into three classes, namely manual, automatic, and autonomous technologies. Manual technology requires constant human interaction for a machine to function; automatic technology executes certain functions automatically without human intervention, but humans retain overall supervision; and autonomous technology allows machines to make decisions without human involvement.

\section{Software technology category}

Software technology comprises computer programmes used for a number of applications in mining. The first of the three classes consists of software used in monitoring and controlling systems. The second class consists of software used for analysis and manipulation of data to enhance decision-making process. The third consists of software used for designing and optimization of systems, including scheduling and layout or mine design.

\section{Mining services technology category}

Mining services technology refers to services that are offered by specialists as input into mining activities. Again, this is divided into three classes. Service and maintenance of machinery and specialized technical services essentially consists of technical services needed by mining engineers but which are not necessarily offered by persons with mining engineering background. The second class consists of services that are offered by mining engineers on consultancy basis. The third class is contract mining.

\section{Discussion}

When the relevant company data was captured and analysed, a number of interesting results emerged, but only the frequency of activities in relation to mining input technologies and the clustering of companies with respect to backward linkages will be discussed. The discussion below to some extent confirms some of the facts that are known about the relationship between the South African mining industry and the economy.

\section{The frequency of activities in relation to mining input technology}

The 390 activities were allocated according to the 12 nodes in Table II to generate activity-based frequency data as shown in Figure 3. It will be noticed that based on the activity frequency per node, there appears to be strong backward linkages with technical support technology (node 10). This means that mining in South Africa has high intensity of demand for services from specialists in vocations outside the discipline of mining, which in a way is a good indication of a backward linkage. The second and third most demanded technologies are single (node 1) and complex (node 2) artefacts respectively. These technologies comprise

Table /I

Twelve nodes of input mining technology

\begin{tabular}{|l|c|c|c|}
\hline & Class 1 & Class 2 & Class 3 \\
\hline $\begin{array}{l}\text { Artefact Technology } \\
\text { Category }\end{array}$ & $\begin{array}{c}\text { Single Artefacts (node 1) } \\
\text { e.g. mine pole; integrate } \\
\text { drill steel; shank }\end{array}$ & $\begin{array}{c}\text { Complex Artefacts (node 2) } \\
\text { e.g. roofbolt; drill bit; idler }\end{array}$ & $\begin{array}{c}\text { Networkable Artefacts (node 3) } \\
\text { e.g. weightometer; heat sensor; collision } \\
\text { avoidance system }\end{array}$ \\
\hline $\begin{array}{l}\text { Machine Technology } \\
\text { Category }\end{array}$ & $\begin{array}{c}\text { Manual (node 4) } \\
\text { e.g. diesel locomotive; rock drill; } \\
\text { scraper winch }\end{array}$ & $\begin{array}{c}\text { Automatic (node 5) } \\
\text { e.g. water pumps; continuous miner; } \\
\text { development rig }\end{array}$ & $\begin{array}{c}\text { Autonomous (node 6) new generation of production rigs and surface } \\
\text { drill rigs. u/g dump truck (Finsch Mine) }\end{array}$ \\
\hline $\begin{array}{l}\text { Software Technology } \\
\text { Category }\end{array}$ & $\begin{array}{c}\text { Monitoring and Control Software } \\
\text { (node 7) }\end{array}$ & $\begin{array}{c}\text { Data Analysis and Manipulation Software } \\
\text { (node 8) }\end{array}$ & $\begin{array}{c}\text { Design and Optimization Software } \\
\text { (node 9) }\end{array}$ \\
\hline $\begin{array}{l}\text { Mining Services } \\
\text { Technology } \\
\text { Category }\end{array}$ & $\begin{array}{c}\text { Technical Support Services } \\
\text { (node 10) e.g. vehicle service and } \\
\text { maintenance; training; installations }\end{array}$ & $\begin{array}{c}\text { Mining Engineering Services } \\
\text { (node 11) e.g. mine design; process } \\
\text { optimization; feasibility studies }\end{array}$ & $\begin{array}{c}\text { Contract Mining Services } \\
\text { (node 12) e.g. drilling and blasting; } \\
\text { development; sweeping and vamping }\end{array}$ \\
\hline
\end{tabular}




\section{The nature of mining input technology in South Africa}

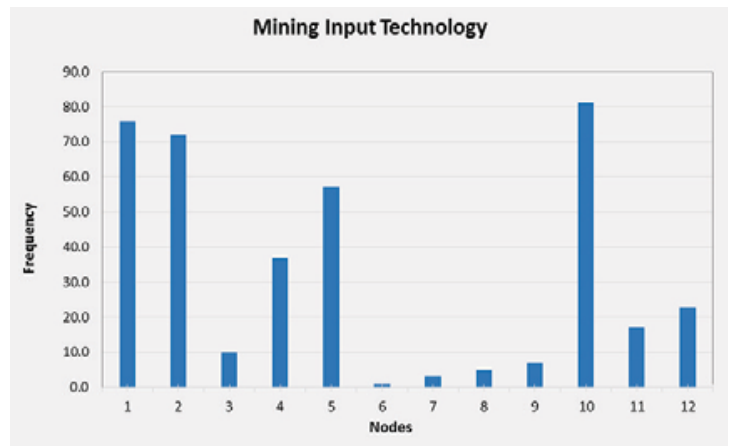

Figure 3-Frequency of mining input technology per node

manufactured goods, which means that mining has strong backward linkages with the light engineering manufacturing sector. This sector is known for its labour absorptive ability.

On the other hand, there are weak backward linkages with autonomous machine technology (node 6) as well as with the software technology category (nodes 7, 8, and 9). This is not surprising when considering that autonomous machines are an emerging technology that has not fully taken effect in South Africa. With respect to software, mining engineers in South Africa are still not reliant on software, at least not to the same extent as other technologies. However as engineering involves design, it is completely realistic to expect South African mining engineers to use design and optimization software more frequently than other types of software, hence the highest frequency in node 9 under the software category.

When mining service technology is excluded and local content (i.e. finance, human resources, ownership, and procurement) is taken into account, it was observed that, in South Africa, mining input technology tends to have a higher local content as shown in Figure 4. In this instance, there are stronger local backward linkages compared to foreign backward linkages (imported technology) with respect to the complex artefact technology (node 2) and weaker backward linkages with autonomous machine technology (node 6). It is interesting to note that there is also a significant level of local backward linkages compared to foreign backward linkages with respect to manual and automatic machine technologies, which supports the assertions of Walker and Jourdan (2003) and Kaplan (2011). In terms of monetary value, although this is not the focus of this paper, machine technology has in general a higher value than artefact technology, and the value of locally manufactured machines (per unit) is less than that of foreign manufactured machines, largely due to the complex nature of imported machines.

When service technology is included and the local content is still taken into account, a slightly different picture emerges (see Figure 5). In this paper, mining service technology is considered as local technology largely due to its reliance on local human resources and the fact that the companies under consideration are registered in South Africa. On the basis of this argument, services that support specific technologies were reallocated accordingly, e.g. service and maintenance of manual machines was reallocated to manual machine technology to reflect higher local content. Only services that do not relate to any other technology were left in their respective nodes. In this respect, nodes $1,2,4,5,7,8$, and 9 were affected.

A comparison of Figure 3 and Figure 5 reveals that when local and foreign technologies are considered jointly, the frequency of node 10 decreases (Figure 5), whereas the frequencies of nodes $1,2,4,5,7,8$, and 9 increase. This is because there are artefacts and mechanical items in nodes 1 , 2,4 , and 5 that need service and maintenance and technical support with respect to nodes 7, 8, and 9. In Figure 5, node 5 has the highest frequency, followed by node 2 , pointing to strong backward linkage to the technician and artisan trades. This gives credence to the importance of these trades in supporting mechanization in mining.

Even after reallocation, node 10 in Figure 5 is still the highest in the mining services category, further indicating the importance of technical disciplines to support mining. Stated differently, if measures are put in place to safeguard against the enclave nature of mining, there is a high likelihood of mines creating job opportunities in the regions in which they are located. Given that in our sample, based on Figure 4 and Figure 5, there are more locally produced inputs than foreign, it can be cautiously concluded that mining in South Africa has induced strong backward linkages.

\section{The clustering of companies}

South Africa has nine provinces, all of which host mining and quarrying operations to varying degrees. Historically the Gauteng Province was a mining province, with industrialscale mining commencing in the late 1880 s after the

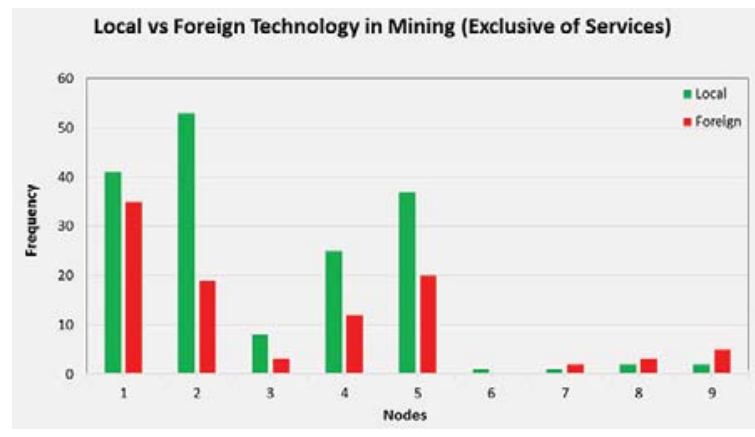

Figure 4-Comparison of local and foreign frequencies per node (excluding mining service technology)

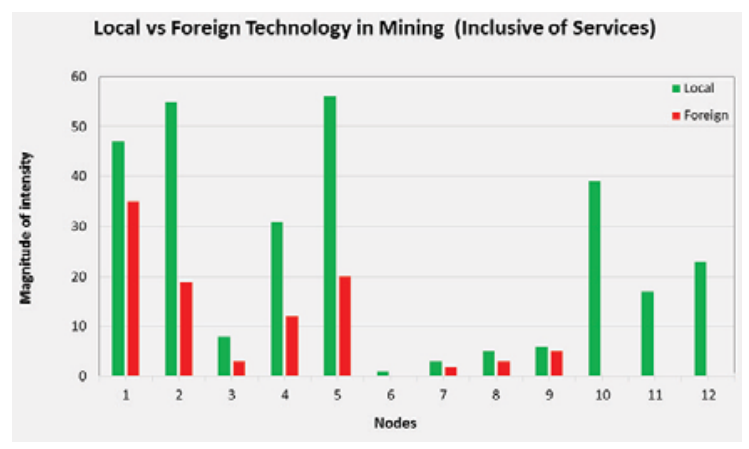

Figure 5-Comparison of local and foreign frequencies per node (including mining service technology) 


\section{The nature of mining input technology in South Africa}

discovery of the Witwatersrand Basin gold deposit. Mining, especially after the World War I, induced industrial supplier activities in South Africa, with Johannesburg emerging as one of the former mining towns successfully transformed into an industrial and commercial hub (Leeuw, 2012).

From 150 the companies in the sample, there are 183 business branches spread throughout South Africa. In Figure 6, it can be seen that Gauteng Province is host to $83 \%$ of these branches, towering over other provinces. From this, it can be concluded that there is a strong backward linkage between mining and supplier companies in Gauteng, despite the province currently having relatively fewer largescalemines than some other provinces. There is a higher concentration of platinum and gold mines in the North-West Province, platinum and chrome mines in Limpopo Province, and coal mines in Mpumalanga Province.

A close analysis of the Gauteng Province (Figure 7) shows that the highest number of business branches (19\%) in the sample are in Johannesburg, followed by Boksburg (14\%) and Kempton Park (12\%). Although there are a number of mines in the Westonaria and Carletonville area, there is only one business branch in the sample in each of these towns. This phenomenon, which also occurs on a national scale, is repeated within the province. The logical conclusion is that traditional business areas have an advantage over emerging areas when competing for contracts in the mines. These could be attributed to the cluster phenomenon as outlined by Porter (2007).

Further analysis of the data showed that manufacturing activity, particularly manufacturing of machines and artefacts, is concentrated in Johannesburg, Boksburg,

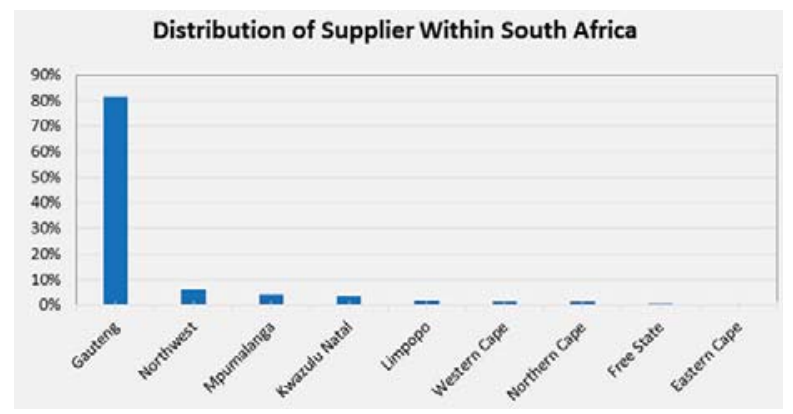

Figure 6-Distribution of mining supplier companies per province in South Africa

Distribution of Supplier Companies Within the Gauteng Province

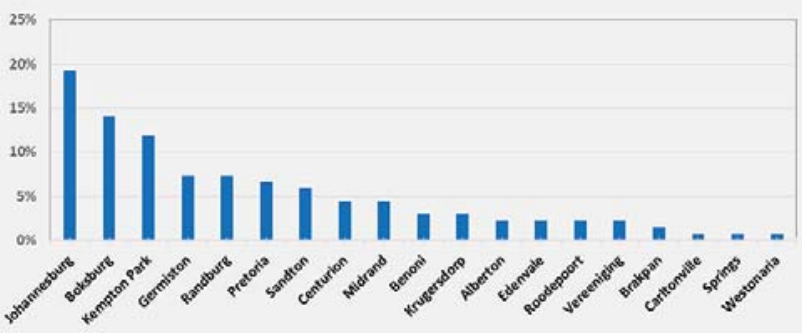

Figure 7-Distribution of mining supplier companies in Gauteng Province
Kempton Park, Germiston, and Randburg. Further out from these centres, there are more retailing and technical support services and fewer manufacturing activities. The concentration of manufacturing activities in the aforementioned centres can be attributed to the clustering effect. It can therefore be stated that local mining is connected to other sectors of the economy largely through Gauteng Province, hence mining backward linkages are skewed towards this province.

\section{Conclusion}

According to Hirschman (1958), backward linkages are important in a developing country for the wellbeing of the economy. Furthermore, he stated that backward linkages can be weak or strong: strong linkages result in the establishment of new industries to provide inputs into the primary industry. In the context of South Africa, the mining industry can be described as strongly linked.

In this paper, the aim was to create understanding of the nature of backward mining linkages in South Africa. Mining input technology was divided into 12 nodes as shown in Table II, and data from a sample of 150 first-tier supplier companies to the mining industry was analysed. The analysis revealed that mining inputs have high local content, pointing to strong backward linkages. In particular, the frequencies of technical support services (i.e. services provided by nonmining occupations) and manufactured artefacts and machines are relatively high. These technologies are strong indicators of backward linkages.

Further analysis showed that $83 \%$ of the branches of the companies in the sample were in the Gauteng Province where most of the activities related to mining input technologies are performed. These activities include light engineering manufacturing, which is known for its labour-absorptive capability. Further away from Gauteng, technical support services and other services like contract mining were significant. From this, it can be concluded that mining induces local backward linkages in South Africa, mostly in Gauteng Province.

\section{References}

African Union. 2009. African Mining Vision. Addis Ababa.

Chamber of Mines of South Africa. 2014. Facts and figures 2013. Johannesburg.

ClAiRmonte, F. 1959. Friedrich List and the historical concept of balance growth. Indian Economic Review, vol. 4. pp. 24-44.

Creamer, M. 2010. South Africa's \$2,5T minerals offer 90-year horizon Abedian. Mining Weekly. http://www.miningweekly.com/article/s-africas25-trillion-mineral-wealth-offers-90-year-wealth-window-iraj-abedian2010-11-22 [Accessed 28 February 2016].

Department of Mineral Resources. 2015. South African's Mineral Industry 2013-2014. Pretoria.

Department of TRAde and Industry. 2015. Facts and figures on skills in manufacturing. Pretoria.

Dlamint-Zuma, N. 2014. Mining in Africa : the African Union's 50-year vision beneficiation \& value addition. New Agenda South African Journal of Social and Economic Policy. pp. 57-59.

Fleming, D. and Measham, T. 2014. Local job multiplier of mining. Resource Policy, vol. 41. pp. 9-14. 


\section{The nature of mining input technology in South Africa}

Hausmann, R. and KLinger, B. 2006. South Africa's export predicament. Harvard University, Working Papers.

HiRschman, A.O. 1992. Rival Views of Market Society and Other Recent Essays. Harvard University Press, Cambridge, MA.

HiRschman, A.O. 1981. Essays in Trespassing: Economics to Politics and Beyond. Cambridge University Press Archive.

HiRschman, A.O. 1958. The Strategy of Economic Development. Yale University Press, London.

JONES, S. and BAXTER, R. 2002. Transformation in the 1990s. The Decline of the South African Economy. Edward Elgar, Cheltenham, UK.

KAPLAN, D. 2011. South African mining equipment and related services: growth, constraints and policy. MMCP Discussion Paper no. 5. Centre for Social Science Research, University of Cape Town.

LeEuw, P. 2012. A linkage model for the South Africa mineral sector: a plausible solution. University of the Witwatersrand, Johannesburg.

Lombard, J.A. and StadLer, J.J. 1980. The Role of Mining in the South African Economy. University of Pretoria, Pretoria.

LowE, P. 1995. Management of Technology: Perception and Opportunities. Springer.

LyDALL, M. 2009. Backward linkage development in the South African PGM industry: a case study. Resource. Policy, vol. 34. pp. 112-120. doi:10.1016/j.resourpol.2009.01.001

MacDonald, S. 1985. Technology beyond machines. Implementing New Technologies: Choice, Decision and Change In Manufacturing. Blackwell/ The Open University, Oxford. p. 416.

MANUfacturing Circle. 2015. Manufacturing Bulletin. Quarterly review: Fourth Quarter 2015. Ferndale, South Africa.

Miтcham, C. 1994. Thinking through Technology: the Path between Engineering and Philosophy. University of Chicago Press, Chicago.

Mtegha, H., LeEUw, P., NAicker, S., and Molepo, M. 2012. Resources corridors: experiences, economics and engagement; a typology of Sub-Saharan African corridors. School of Mining Engineering and Centre for Sustainability in Mining and Industry (CSMI), University of the Witwatersrand, Johannesburg.

PorTer, M. 2007. Clusters and economic policy: aligning public policy with the new economics of competition. ISC White Paper no. rev. 10/27/09. Harvard Business School, Boston, MA..

Robinson, I. and von Below, M. 1990. The role of the domestic market in promoting the beneficiation of raw materials in South Africa. Journal of the South African Institute of Mining and Metallurgy, vol. 90. pp. 91-98.

Statistic South Africa. 2014. Annual financial statistics 2013. Republic of South Africa, Pretoria.

Streeten, P. 1959. Unbalanced growth. Oxford Economics Papers, New Series, vol. 11. pp. 167-190.

WALKER, M. and JoURDAN, P. 2003. Resource-based sustainable development: an alternative approach to industrialisation in South Africa. Mineral Energy, vol. 18. pp. $25-43$.

\section{Appendix A}

Breakdown of company activities using the Standard Industrial Classification (SIC) code

Code Description

1399 Manufacture of other textiles n.e.c.*

1410 Manufacture of wearing apparel, except fur apparel

1520 Manufacture of footwear

2011 Manufacture of basic chemicals
Manufacture of explosives and pyrotechnic products Manufacture of rubber tyres and tubes; retreading and rebuilding of rubber tyres

Manufacture of plastic hoses and belts and other plastic products,

Manufacture of sheet piling of steel and welded open sections of steel

Manufacture of structural metal products

Manufacture of other fabricated metal products

n.e.c.*

Manufacture of computers and peripheral equipment Manufacture of communication equipment

Manufacture of measuring, testing, navigating, and control equipment

Manufacture of electric motors, generators, electricity distribution, and control apparatus Manufacture of batteries and accumulators Manufacture of other electrical equipment, motors,

Manufacture of engines and parts

Manufacture of fluid power equipment

Manufacture of other pumps, compressors, taps, and valves

Manufacture of bearings, gears, gearing, idlers, and driving elements

Manufacture of lifting and handling equipment

Manufacture of machinery for mining, quarrying, and construction

Building of ships and floating structures

Manufacture of plastic hard-hats and other personal safety equipment from plastics

Other manufacturing n.e.c.*

Repair of machinery

Repair of electronic and optical equipment

Repair of transport equipment, except motor vehicles

Installation of industrial machinery and equipment Other specialized construction activities

Sale of motor vehicle parts and accessories

Wholesale of other machinery and equipment

Retail sale of computers, peripheral units, software, and telecommunications

Retail sale of audio and video equipment in specialized stores

Other retail sale of new goods in specialized stores Other retail sale of new goods in specialized stores Computer programming activities

Computer consultancy and computer facilities management activities

Specialized design activities

Other professional, scientific, and technical activities n.e.c. ${ }^{*}$

Renting and leasing of other machinery, equipment, and tangible goods

Other education n.e.c. ${ }^{*}$ quarrying n.e.c. 